\title{
Chapter 5 \\ Effect of Emotion and Personality on Deviation from Purely Rational Decision-Making
}

\author{
Marina Fiori, Alessandra Lintas, Sarah Mesrobian, and Alessandro E.P. Villa ${ }^{\star}$
}

\begin{abstract}
Human decision-making has consistently demonstrated deviation from "pure" rationality. Emotions are a primary driver of human actions and the current study investigates how perceived emotions and personality traits may affect decision-making during the Ultimatum Game (UG). We manipulated emotions by showing images with emotional connotation while participants decided how to split money with a second player. Event-related potentials (ERPs) from scalp electrodes were recorded during the whole decision-making process. We observed significant differences in the activity of central and frontal areas when participants offered money with respect to when they accepted or rejected an offer. We found that participants were more likely to offer a higher amount of money when making their decision in association with negative emotions. Furthermore, participants were more likely to accept offers when making their decision in association with positive emotions. Honest, conscientious, and introverted participants were more likely to accept offers. Our results suggest that factors others than a rational strategy may predict economic decision-making in the UG.
\end{abstract}

\subsection{Behavioural Economics of Ultimatum Game and Emotion}

Traditional economic models emphasise the importance of rational choices [115]. In this framework humans could be replaced by "rational agents", being purely

Marina Fiori, Alessandra Lintas, Sarah Mesrobian, Alessandro E.P. Villa Neuroheuristic Research Group, University of Lausanne, Switzerland e-mail: \{marina.fiori, alessandra.lintas, sarah.mesrobian, alessandro.villa\}@neuroheuristic.org

Marina Fiori

Department of Organizational Behavior, University of Lausanne Faculty of Business and Economics (HEC)

Alessandra Lintas

Dept. of Medicine/Unit of Anatomy, University of Fribourg, Switzerland

$\star$ Corresponding author. 
self-interested and described as "cold gain maximiser", or Homo Economicus [112]. According to these models, when a rational agent chooses between two options, it will compute the utility of outcome of both choices, estimate their probability of occurrence, and finally select the one that offers the highest gain. This assumption sets the foundation of the existence of "utility functions" capable to compute an "expected" value. The perceived value of a good can be considered equivalent to a measure of satisfaction and to the expectation to attain specific outcomes. Such a framework is rooted in the Western world and well illustrated by the famous statement made by the Swiss mathematician Gabriel Cramer on 21 May 1728. At that time he was in London and addressing a letter to his compatriot and fellow mathematician Nicolas Bernouilli in Basel he wrote:

The mathematicians estimate money in proportion to its quantity, and men of good sense in proportion to the usage that they may make of it [97].

Indeed, in the "Theory of the Consumer" it is assumed that rational individuals maximise the consumption of real goods given a limited availability of nominal goods (money) [103, 104]. Then, according to the initial assumptions, the observed choice is the best way to infer the underlying consumer's maximised utility function, i.e. their "willingness-to-pay":

Utility is taken to be correlative to Desire or Want. It has been already argued that desires cannot be measured directly, but only indirectly, by the outward phenomena to which they give rise: and that in those cases with which economics is chiefly concerned the measure is found in the price which a person is willing to pay for the fulfilment or satisfaction of his desire [81].

Rather than performing empirical tests of the utility maximisation hypothesis, much research has taken for granted that the expected value is equivalent to the revealed preference [59]. However, there is little empirical evidence concerning whether individual demands satisfy the revealed preference axioms [49]. In contrast, research has shown that human behaviour is far from being economically rational and humans failed to reproduce the behaviour of the pure rational agents. One of the main reason of this finding is that goals and wishes may change, adapt or even vanish in a very short time. These observations opened a way to new research paradigms emphasising heuristics and biases in decision-making under uncertainty and choice under risk. This new approach led to the development of "prospect theory" and the concept of "bounded rationality" [15,63]. According to this theory, people make decisions based on the potential worth of the losses and the advantages and make decisions applying individual heuristics derived from one's experience and learning.

A further step for the development of a more comprehensive framework of behavioural economics is achieved by including the social dimension. Human subjects develop and evolve within a social framework and their sense of rationality cannot be separated from the outcome of interpersonal interactions. Living in a social world, there is no scarcity of situations in which we give and take, buy and sell. While doing their shopping, people have their own money at their disposal and if their willingness-to-pay for a certain item lies above the owner's willingness-tosell, then money and item are transferred, otherwise no deal is made. One party, the 
"proposer", offers to sell an item with the intention to maximise his income, and the other party, the "responder", can either accept or reject the offer with the intention to maximise his saving. Let us assume that responder's savings correspond to an income that the responder made in another transaction when he played the party of a proposer. If we extend this concept to real-life situations we can assume that each party is driven to maximise his income and his saving iteratively in a sequence of transactions. The maximisation of income and savings can be achieved by maximising the "willingness-to-share". Such a real-life situation may occur when one party, the proposer, offers how to split a limited resource (e.g., a sum of money). If the other party, the responder, accepts the deal, the resource is distributed according to the proposal, and if he rejects, both parties get nothing. This kind of situation is close to an iterative implementation of the Ultimatum Game (UG) [46], which is originally a one-shot bargaining game with no communication and no negotiation.

According to Game Theory, the subgame perfect equilibrium in the Ultimatum Game [102] is that the proposer offers the smallest possible amount (in order to save as much as possible), and the responder accepts any amount (because a small amount is better than nothing). A selfish income-maximiser should accept all offers, even very low, as it is always a positive gain. Anticipating such a rationale of the responder, the proposer should always offer the smallest possible amount to the responder and keep the largest possible amount for himself. Experimental findings do not confirm this prediction. Interestingly, rather than assuming they are playing with "rational" players and, thereby, proposing very lopsided divisions, most proposers offer to share the sum in a proportion close to 50/50. Proposers tend to offer rather fair offers and responders' tend to reject offers that are judged as unfair (e.g., less than 20 percent of the total amount), even under large increases in stakes [14,109] despite this being an irrational behaviour with respect to gain maximisation [51, 100].

This deviation from "rational" strategies that are suggested by game-theoretic analysis can be explained by the fact that humans cannot put aside the assumption of being in a multi-player, multi-round environment they are accustomed to in the real world. Such environment includes "irrational" concepts such as fairness and adaptation to societal expectations [19] and is in agreement with the concept of "willingness-to-share". The substantial role played by emotions in decision-making and behaviour in a multi-player environment is expressed by concepts like "fairness" and "social sharing" that involve the description of an emotional event by the person who experienced it to another person in a socially-shared language [74]. It appears that the proposers behave as they know already they are playing with "emotional" rather than "rational" players. Lopsided divisions are not often proposed but, when they are, they are often rejected. Both proposers and responders do not behave according to pure rationality and make decisions far from the Homo Economicus's rational choice. An hypothesis that has been suggested to explain this divergence is that participants to UG behave according to the logic of fairness and reciprocity, thus punishing unfair players by refusing low offers [34, 35]. A "fair" share is "irrationally" expected by the participants and they will accept nothing less. The fact that reciprocity plays a role in economical decision-making is also supported by 
the fact that the rejection rate is lower when the proposer is a computer rather than a human being [118] suggesting that "retaliation" is specifically addressed to other human beings rather than to virtual players. Fairness and reciprocity are mental biases observed across all human cultures. They are likely to be determined by learning by "imitation", which is the earliest interpersonal behaviour occurring before the end of brain maturation, and the possibility to build-up cross-temporal contingencies [1, 38, 61]. Whether these biases are the foundation of a human innate moral psychology or not is a question that goes beyond the scope of this study.

Emotions are powerful drives that affect the decision to accept or reject a monetary offer. For instance, participants who were induced to feel sadness were more likely to reject unfair offers in a monetary exchange game [50]. Research on negotiation behaviour includes the investigation about how emotions and emotional display affect interdependent decision-making. In this context emotional states and the display of emotions are regarded as predictors of negotiated outcomes [70]. Affect can be used as a cue that discriminates between options [110] and that evaluates the attributes of an option (e.g., the attractiveness or prestige) even prior to decision-making [60,77]. Displayed emotions, whether positive or negative, may influence social interactions because they convey satisfaction with the behaviour of other player. Furthermore, displayed emotions influence strategic information processing [36] and may serve as means of persuasion. In a UG study, induced positive emotions appear to increase cooperative behaviour while negative affect may have an opposed impact [95]. People in negotiation seem to reciprocate their opponent's emotions [66]. They get angry when confronted with an angry opponent and happy when confronted with a happy opponent [37]. In other UG studies it was observed that proposers who displayed negative emotions elicited by emotional faces, prior to making an offer, were more likely to reject offers when they played the role of responders than those displaying either neutral or positive emotions [70]. Primates tend to identify themselves with the other party in most interpersonal interactions [41,99]. Then, the strong affective power associated with emotional faces may bias the study of emotions sensu stricto on decision-making.

This Chapter is organised as follows. In relation with decision-making processes we review at first the background of the neurobiology of emotion in Section 5.2 and, secondly, the main characteristics of the brain electric signals -event-related potentials- recorded on human scalp in Section 5.3. The detailed description of the experimental task aimed at studying the effect of emotions evoked by non-figurative pictures in the Ultimatum Game paradigm is described in Section 5.4 In Section 5.5 we present the behavioural and the electrophysiological results. A discussion is added in Section 5.6

\subsection{Neurobiology of Emotion and Decision-Making}

Decision-making is considered the most essential phase in volitional act. This is supposed to occur in the temporal window that follows sensory processes [23] and 
before the motor response confirms that a decision was made. Patients suffering certain brain lesions tend to make "bad" decisions, even when biases and heuristics of normal "irrational" subjects are taken into consideration. Decision-making is overall impaired in certain patients as if they were unable to learn from previous mistakes or if they were unable to process correctly the perceived information [4, 25]. Understanding the neural basis of decision-making processes (the Somatic Markers Hypothesis) is a key question which is generally investigated by searching where and how a "decision" is made in a recursive way.

Neuroimaging techniques applied to the investigation of the neurobiological basis of economic games suggest that the brain employs multiple systems of processes in decision-making [3, 98, 106, 126]. These studies focused on the identification of the respective rational and emotional contributions to decision-making, despite the fact that cognition and affect might be considered inseparable [29]. Cognitive-based judgements underlying decision-making were investigated taking into consideration language, attention, and working memory systems [105]. Cognition may be regulated by affect [111] and mood [101]. In many types of decision processes, including moral judgement [71] and economic decision-making [106], experimental observations reported the activation of an emotional pathway in the brain. The neurobiological studies of the entire process of decision-making during economic tasks, from the initial perception of a "stimulus" (which conveys new information and/or new investment options), to valuation and motivation, and the very act of choosing, highlight the limitations of utility theory postulated by standard economic models [8]. Figure 5.1 illustrate the main areas involved in processing and integration of emotional information [12,108].

Certain regions of the brain are activated when perceiving unfairness. In particular, the bilateral anterior insula, the dorsolateral prefrontal cortex (DLPFC) and the anterior cingulate cortex (ACC) were involved in processing unfair offers from human proposers [106].

In the same study participants that showed stronger anterior insula activation to unfair offers rejected a higher proportion of these offers. This result may support the assumption that neural representations of emotional states guide human behaviour. Interestingly, the anterior insula is often associated with negative emotional states such as pain, distress or disgust.

The DLPFC appears to be an area involved in planning ahead, goal maintenance and executive control [38, 83, 106]. The observation that unfair offers tended to activate DLPFC [106] suggested that this area may be associated with the representation and active maintenance of the cognitive demands of the task, achieving the maximum amount of money. In addition, rejecting unfair offers in the UG was associated with higher physiological activation as measured by skin conductance [118].

In the Ultimatum Game ACC activity can be associated with the detection of a cognitive conflict, such as presence of contrasting responses and may reflect the conflict between cognitive and emotional motivations [9]. The ACC, a structure located on the medial surface of the frontal lobes (Fig. 5.1) has diverse functions. It can be subdivided into areas related to cognition and affect [13, 114]. The dorsal regions of the ACC represent the cognitive subdivision, being crucial for error 

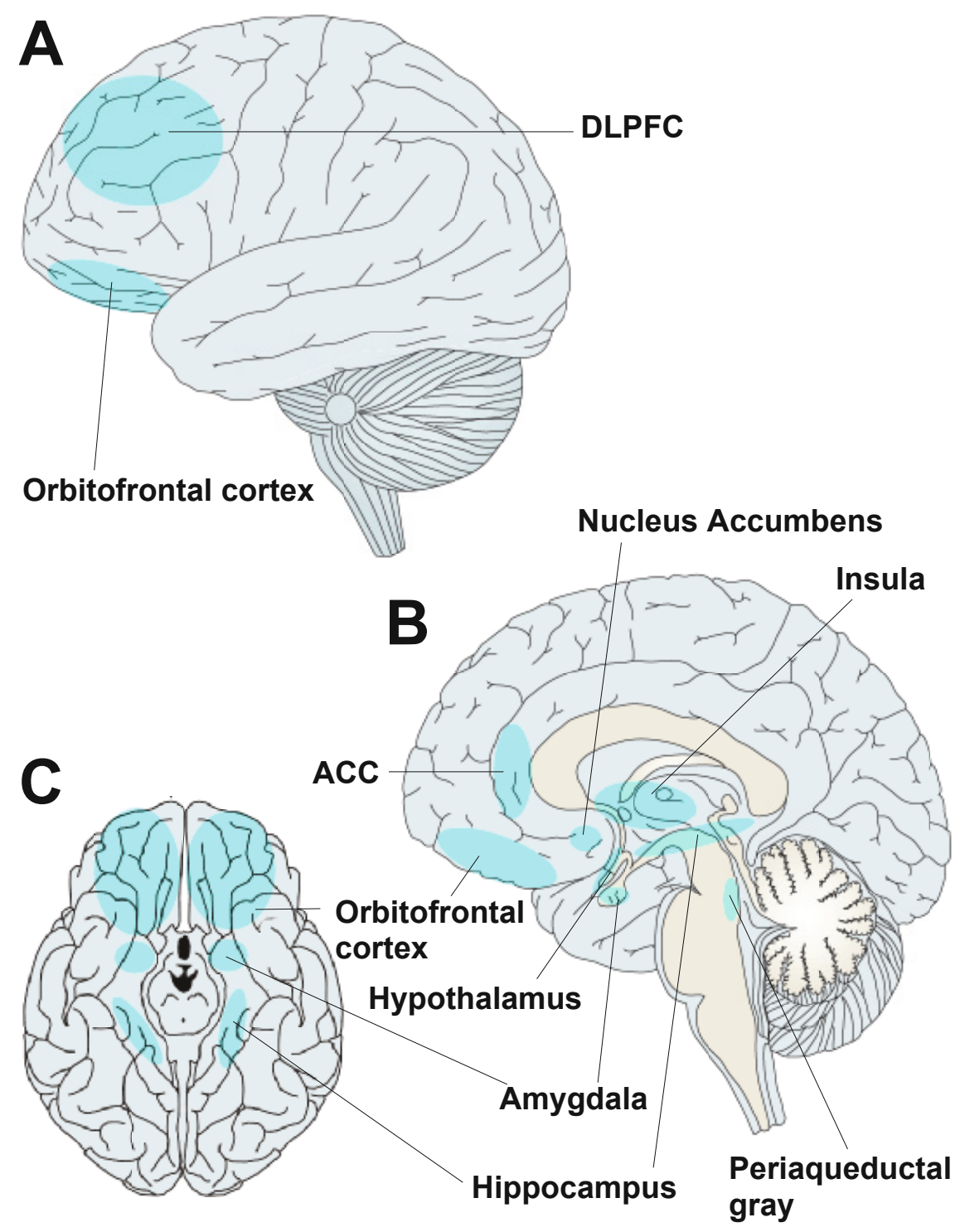

Fig. 5.1 Human brain illustration of lateral surface of the right cerebral hemisphere (A), medial surface of the left cerebral hemisphere (B) and the inferior view (C).

processing [18] and for mediating processes such as response inhibition [13]. Caudo-dorsal regions of ACC share further connections with other neural systems involved in reward processing and decision-making, such as the mesencephalic dopamine system [24] and the orbitofrontal cortex [55]. The rostro-ventral 
ACC corresponds to the affective subdivision, and is connected to the amygdala, periaqueductal gray, nucleus accumbens, hypothalamus, hippocampus, anterior insula and orbitofrontal cortex [28]. ACC activation upon receiving low offers in the UG can also be associated with unfairness, i.e. the occurrence of outcomes that are not as good as expected [56].

\subsection{Event Related Potentials}

Electroencephalography (EEG) is the most widely used method to record human brain activity with high temporal resolution ( $1 \mathrm{~ms}$ time scale) in a non-invasive way from the human scalp by means of external electrodes placed over many standard locations determined by skull landmarks. Transient electric potentials associated in time with a physical or mental occurrence are termed event-related potentials (ERPs) [94]. The ERP is extracted from the ongoing EEG by means of signal filtering and averaged over many responses to a triggering event associated with cognitive activity involved in stimulus processing and/or action preparation. Although ERPs can be evaluated in both frequency and time domains, we focus attention on ERPs recorded in the time domain, i.e. the curves obtained by averaging electric potential shifts as a function of time over several trials and across participants. In the temporal domain "early" and "late" components of ERPs [113] have been extensively studied and recognizee in the vast majority of experimental paradigms.

The early responses (10-50 $\mathrm{ms}$ after the triggering event) reflect the activity of sub-cortical circuits and primary cortical areas. Physical features of the stimulus are the main determinants of a large complex of waves labelled N75-P100-N145, with latencies peaking at about 75, 100 and $145 \mathrm{~ms}$ recorded over the posterior region of the scalp. These waveforms are considered "exogenous" components thought to reflect the physical characteristics of the eliciting event in the external world. At latencies starting around $150 \mathrm{~ms}$ from the eliciting event the waveforms contain ERP components considered as "endogenous", thought to be associated with brain activity that may or may not be invoked by the eliciting event. The difference between ERPs to attended vs. unattended stimuli shows a negative difference $(\mathrm{Nd})$ peaking at a latency of 140-200 $\mathrm{ms}$. The negative difference is formed by an early posterior component $(\mathrm{Nd} 1)$, which is associated with a process comparing the sensory input and an attentional trace in the primary sensory cortex, and a fronto-central component $(\mathrm{Nd} 2)$, which is related to the control and maintenance of the attentional trace [42].

A positive component occurring in the interval between 150 and $280 \mathrm{~ms}$ and peaking at about $200 \mathrm{~ms}$ after the stimulus onset is called P200 (or P2). The visual P200 can be measured by electrodes over the anterior and central sites of the scalp, and over the parieto-occipital region, but it is usually maximal over the frontal region. In addition to be a part of the normal response to visual stimuli P200 is modulated during performance of cognitive tasks associated with visual search in memory or language context and attentional processes. It has been suggested that P200 
is related to higher-order processes that involve the comparison of the eliciting event of the ERP with its internal representation or expectation [32, 78]. A recent study showed a P200 component, presumably generated by orbitofrontal cortex, associated with an economic decision and its occurrence was thought to reflect an early assessment of the outcome with P200 amplitude correlated with risk-taking [96]. P200 is also associated with emotional evaluation [16], in particular with the subjective negative valence of emotional images, the stronger emotional negativity the larger P200 amplitude [17]. Anger faces elicited greater P200 amplitudes than pain and neutral faces [44].

A negative deflection or shift is observed in the ERP at latencies peaking approximately at 250-300 $\mathrm{ms}$ when subjects receive feedback information about the correctness of the performance [33, 39]. This error-related negativity is likely to be associated with a general neural process involved in error detection in different situation and contributes to the difference between correct and incorrect feedback conditions (i.e. Go-NoGo task) [84].

Depending on the sensory modality and on the experimental protocol the components may vary in peak latency and amplitudes, such that it should rather be better to consider this error-related negativity corresponding to a family of negativities related to a mismatch as a whole, such as the Mismatch Negativity [31, 88], N400 [72, 73], medial frontal negativity and feedback error-related negativity [40, 58]. Then, this complex of error-related negativity components may be referred to as feedback-related negativity (FRN).

FRN has been proposed to reflect a neural response to negative reward prediction errors [56] and it is associated with reinforcement learning based adjustment of decision values [20]. It is unclear whether the magnitude of the FRN is also modulated by reward expectation. In two studies [58,122], the magnitude of the FRN was larger when outcomes were unexpected but it remains unclear whether FRN was associated only to wins or to both wins and losses. In another study, the FRN tended to be larger for unexpected than expected outcomes but no statistically significant modulation was observed [47]. FRN has also been observed after outcome-based adjustment of decision values [22] but larger FRN amplitudes for negative feedback only emerged significantly for the lowest outcome probability [69]. Using tasks in which subjects could gamble a small or large amount of money on each trial monetary losses were associated with a larger FRN than monetary gains [124]. However, the magnitude of the FRN was insensitive to whether the losses were small or large, such that the FRN appears to be related to the simple bad versus good appraisal of feedback [48]. On the opposite, there is an evidence FRN is modulated in responders by fairness of the offer [96]. The amplitude of FRN was more pronounced for unfair offers, and this was accentuated for participants with high concern of fairness [7]. The precise source localisation of such a complex ERP component is controversial [91] but FRN amplitude tends to be maximal at fronto-central scalp electrode sites [47] the main generator is likely to be located in the dorsal regions of the ACC [85]. 


\subsection{The Present Study}

The aim of the present research is to further extend the understanding of emotional reactions in economic decision-making by investigating the role of basic emotions (happiness, anger, fear, disgust, surprise, and sadness) [30] and personality traits in an iterative sequence of trials based on the Ultimatum Game [45]. This task has been widely used to investigate human interaction, in particular the differences between behaviour expected according to the "rational" model of game theory and observed "irrational" behaviour. Yet, very few studies have looked at the effect of emotions and personality on players's economic behaviour [106]. In the current study, participants played the UG using a computer interface while abstract images were displayed in the background of the computer monitor.

We wanted to study whether and how the emotional feelings elicited by those images could affect participants' decision-making while they were engaged in proposing or accepting an offer. In addition, we investigated the role of individual differences, in particular the personality characteristics of honesty-humility, emotionality, extraversion, agreeableness, conscientiousness, and openness to experience [2] as factors potentially affecting the willingness-to-share. We also explore the neurobiological correlates of the decision-making process, extending our previous study [113]. In particular, we present here the ERPs associated with sub-processes of emotional salience detection (P200), combining incoming information into an emerging emotional representation (FRN), as well as decision-making stages (as indicated by behavioural results) in all participants.

\subsubsection{Participants}

Thirteen volunteers (all males, aged 18-44 years, $M=27.6 \pm 1.8 \mathrm{yrs}$ ) ) took part in the study. All had normal or corrected-to-normal vision, none reported a history of sustained head injury, and all were naive to the Ultimate Game. They were informed about the UG test at the beginning of the study and provided written consent for their participation in line with the Declaration of Helsinki [117. The participants were comfortably seated in a sound- and light-attenuated room, watched a computer-controlled monitor at a distance of $57 \mathrm{~cm}$, and were instructed to maintain their gaze on the center of the monitor throughout the experiment. Participants volunteered to participate in the study and played with virtual money. They were not incentivated by a real payoff, their motivation being the challenge to get the best score and contribute to scientific investigation. Our choice to avoid a real payoff was also motivated by the contrasting results reported on the association of performance with a real payoff [43].

\footnotetext{
${ }^{1} \mathrm{M} \pm \mathrm{SEM}$, Mean \pm Standard Error of the Mean.
} 


\subsubsection{Experimental Task}

The Ultimatum Game (UG) is an anonymous, single-shot two-player game, in which the "proposer" (Player 1) has a certain sum of money at his disposal and must propose a share to the "responder" (Player 2). The responder can either accept or reject this offer. If the responder accepts the proposal, the share is done accordingly. However, if the responder refuses, both players end up with nothing. In the original version [45] the game ends after the responder's decision. In our version each participant played both the role of the proposer (90 trials, Figure 5.2 A) and of the responder ( 90 trials, Figure 5.2 $\mathrm{B}$ ) in three alternated blocks of 30 trials each. Each trial started with a preparatory period of 2 seconds during which participants were instructed to maintain their gaze on a central fixation cross on the computer monitor. The overall experiment lasted about 70 minutes.

The instructions about the task were provided on the computer monitor and the UG was implemented using the E-Prime software? Participants were told to play the UG trying to maximise their gain as much as possible. Each UG trial involved a take-it-or-leave-it integer split of 10 Swiss francs (CHF). The decision regarding whether the responder accepted or refused was conveyed through a face diagram (a smiley) that either smiled or frowned. Participants in the study played against a second player that was in fact a computer program (virtual player), even though participants were not told explicitly (task instructions mentioned a generic "second player"). The economic strategy implemented by the virtual player was set according to a fair strategy such that offers in the range 3-7 occurred equally with a frequency of $14.29 \%$ each, and offers of extreme values 1, 2, 8, or 9 CHF occurred equally with a frequency of $7.15 \%$ each. At the end of the session, the participants were not asked about the other party, but many of them spontaneously reported that they guessed the other party was another human, the experimenter. If they asked whether this was true, the experimenter replied that the other party was a virtual player programmed to play according to observed human strategies. The E-prime software was used for stimuli presentation, marker sending and response recording and the instruction were presented in the written form.

In order to investigate the effect of emotions on the willingness-to-share we included selected emotional artworks painted by Rose Coleman that were presented on the computer monitor in the background, while participants made their decisions. Pictures numbered 754, 1079, 1232, 850, 1215 and 1418 in the artist's catalogue (http://Www.resecoleman.de/eng/) were used in this study. The selection was proposed by the artist herself. This kind of subtle emotional priming was chosen to avoid that participants explicitly realised that we were priming an emotional reaction. In fact, becoming aware of an emotional state may hamper the effect of emotion on subsequent behaviour. Thus, we asked participants to make their economic decisions without mentioning the images in the background. At the end of the experiment we asked participants to rate the emotional content of the images. They indicated the degree to which each picture evoked the six basic emotions of joy, fear, sadness, disgust, anger, and surprise [30] using a scale from 1 = "not at

\footnotetext{
${ }^{2}$ Psychology Software Tools, Inc., Sharpsburg, PA 15215-2821, USA.
} 


\section{A Human Proposer}

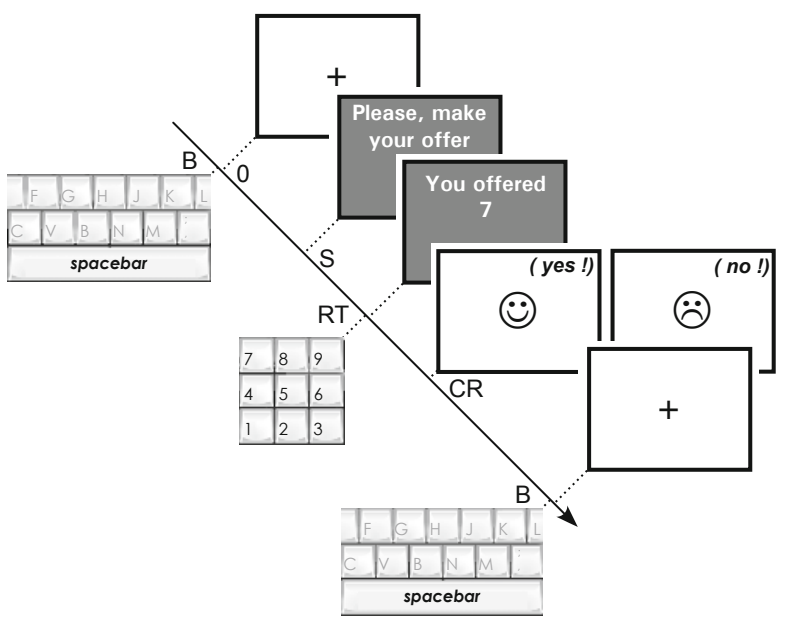

B Human Responder

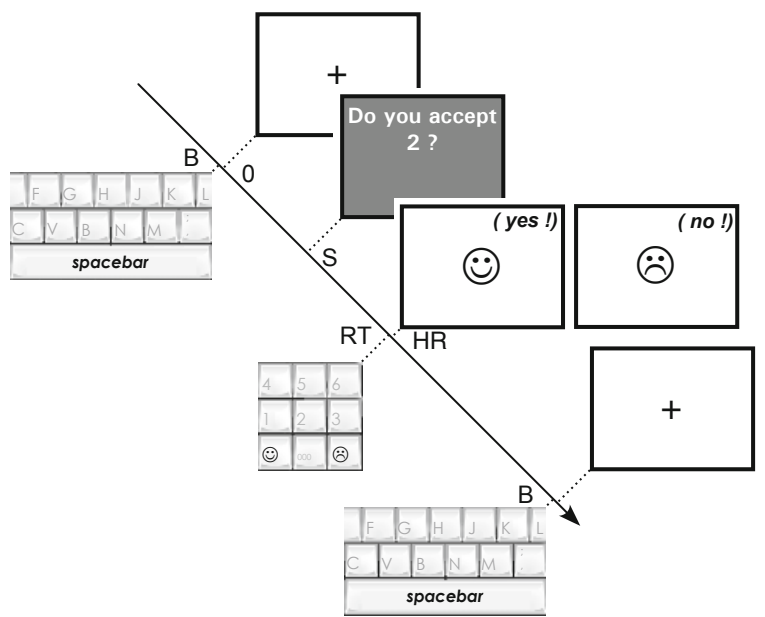

Fig. 5.2 Illustration of the Ultimatum Game task along series composed of two Blocks. During the first Block the participants acted as proposers (A), whereas during the second Block the computer made the offer and the participants acted as responders (B). 
all" to 9 = "very much". We also administered a 60 item personality questionnaire, the French version of the HEXACO-60 personality questionnaire derived from lexical studies [2]. This questionnaire measures trait-specific facets of the personality named Honesty-Humility (H: with descriptive adjectives such as sincere, honest, faithful, loyal, modest/unassuming against sly, deceitful, greedy, pretentious, hypocritical, boastful, pompous), Emotionality (E: emotional, oversensitive, sentimental, fearful, anxious, vulnerable against brave, tough, independent, self-assured, stable), Extraversion (X: outgoing, lively, extraverted, sociable, talkative, cheerful, active against shy, passive, withdrawn, introverted, quiet, reserved), Agreeableness (A: patient, tolerant, peaceful, mild, agreeable, lenient, gentle against ill-tempered, quarrelsome, stubborn, choleric), Conscientiousness (C: organised, disciplined, diligent, careful, thorough, precise against sloppy, negligent, reckless, lazy, irresponsible, absent-minded), and Openness to Experience (O: intellectual, creative, unconventional, innovative, ironic against shallow, unimaginative, conventional).

\subsubsection{Electrophysiological Recordings}

Continuous EEG was recorded using 60 scalp $\mathrm{Ag} / \mathrm{AgCl}$ active electrodes 3 mounted on a headcap (NeuroSpec Quick Cap) and referenced to the linked earlobes (Fig. 5.3). Electrophysiological signals were sampled at $2048 \mathrm{~Hz}$ with lower cutoff at $0.05 \mathrm{~Hz}$ and upper cut-off at $200 \mathrm{~Hz}, 24$ bit resolution 4 . Electrode impedances were kept below $5 \mathrm{k} \Omega$ for all recordings. Vertical and horizontal ocular movements were also recorded using two pairs of bipolar electrodes. Before the begin of the UG trials we recorded two minutes of EEG with the participants seating quietly with closed eyes and two minutes with open eyes maintaining their gaze on a central fixation cross on the computer monitor. Participants performed all UG trials while EEG data were recorded.

Markers corresponding to the spacebar press for the begin of a trial (B at time 0 , Fig. 5.2), stimuli presentations (S for proposer and responder offer types, Fig. 5.2), button press for participant's response time (RT, Fig. 5.2) and responder's choice (CR and HR for virtual player and human responder, respectively, Fig. 5.2) were generated using E-Prime 5 and were inserted in the continuous EEG file. Markers were used off-line to segment the continuous EEG data into epochs time-locked to stimulus onset. The EEG recordings were analysed with the software BrainVision Analyzer v2.0.26. The EEG signals were automatically cleared of movement artifacts in which voltage exceeded $100 \mu V$ and the remaining trials were inspected visually to control for minor artifacts. The epochs were further scanned for contamination by muscular or electrode artifacts and the remaining trials were inspected visually to control for residual minor artifacts.

\footnotetext{
3 (ActiveTwo MARK II Biosemi EEG System, BioSemi B.V., Amsterdam, The Netherlands).

${ }^{4}$ DC amplifiers and software by Biosemi, USA.

${ }^{5}$ Psychology Software Tools, Inc., Sharpsburg, PA 15215-2821, USA.

${ }^{6}$ Brain Vision LLC, Morrisville, NC 27560, USA.
} 

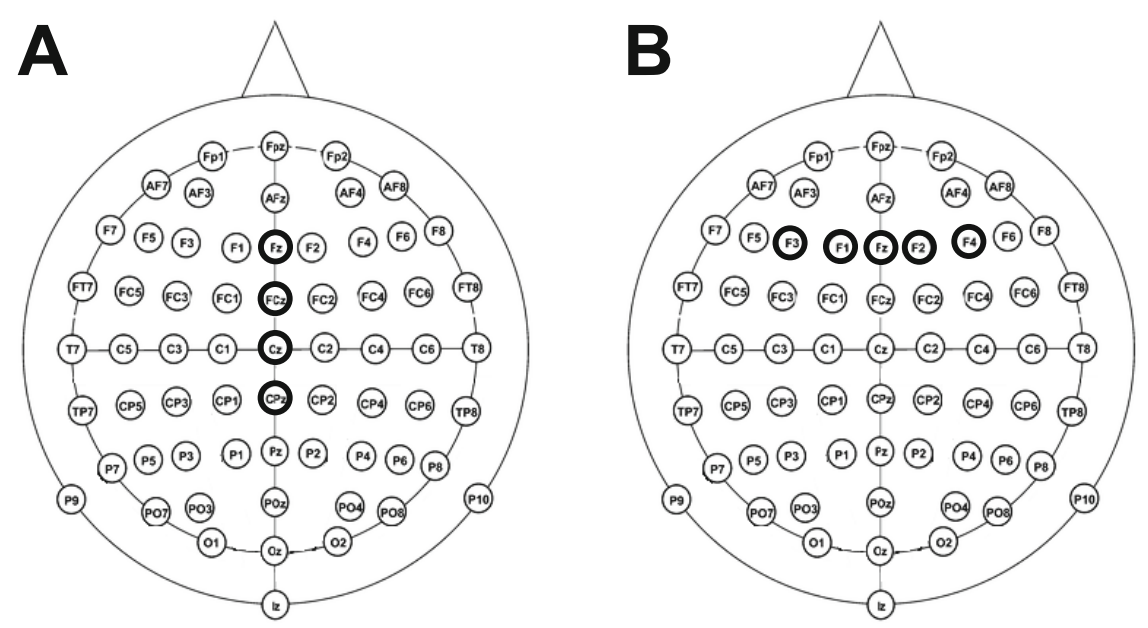

Fig. 5.3 The electrode position of a standard 64 channels montage in the international 10/20 system. A: thick circles report to the midline electrodes referred later, see Fig. 5.6 B: thick circles report to the frontal electrodes referred later, see Fig. 5.7

ERP analyses were performed on the artifact-free trials, band-pass filtered between 0.3 and $30 \mathrm{~Hz}$ (-48dB/octave). ERPs were obtained by averaging the EEG signal on an analysis window corresponding to time intervals lasting $1000 \mathrm{~ms}$, starting $200 \mathrm{~ms}$ before the stimulus onset (marker S) and with a $200 \mathrm{~ms}$ pre-target baseline. Latencies of the ERP components were measured at the time of the maximum peak for proposer and responder conditions. For the P200 and FRN components we focused on the medial $(\mathrm{Fz}, \mathrm{FCz}, \mathrm{Cz}, \mathrm{CPz})$ and the frontal line (F3, F1, Fz, F2, F4) electrode sites in both proposer and responder conditions (Fig. 5.3).

Blind source separation of a linear mixture of evoked electrophysiological data into temporally independent and spatially stationary sources was performed using the independent component analysis (ICA) [79,80]. The EEGLab 9.0.5.6b implementation [27] of the extended infomax algorithm was applied with default settings to ERPs recorded over all 60 electrodes, for all tasks simultaneously. Since the iterative optimisation used in the infomax algorithm has random components (random weight matrix and random data reordering), three separate runs were performed to empirically verify results stability. We report here results of ICA components reproducible from run to run reported in the UG without the emotional priming [87] because they illustrate the main sources of the brain activity elicited in the proposer and responder conditions. The "percent total variance accounted for" gives an idea of how well each ICA component captures the dynamics of the ERP. This can be obtained for each component by back-projecting the component and computing the ratio of the variance of (ERP minus backprojection) to the overall variance of the original ERP. 


\subsection{Results}

\subsubsection{Overall Gain in Each Experimental Condition}

Results were analysed through the statistical package SPSS version 19.07 and Stata version 12.08. The analysis showed that offers were overall centred around the mean for both virtual $(M=5.0, S D=2.2)$ and human $\operatorname{proposer}(M=5.0, S D=1.5)$.

Yet, the observation of frequency of offered values shows a different pattern for the two experimental conditions. Most human proposer's offers ranged between 6-4 and 5-5, whereas virtual proposer's offers were set to include a higher number of unbalanced offers, such as 8-2 and 2-8. Moreover, the number of accepted offers was significantly higher by human responders $(M=67.1$ out of 90 trials, $S D=11.2)$ than by virtual responders $(M=51.9, S D=9.7)$, as demonstrated by the level of significance $p$ of the test $\mathrm{F}$ that compares whether the two mean values are significantly different: $F(1,25)=13.99, p=0.00110$.

We analysed the total gain obtained by each player and its counterpart in each experimental condition. Figure 5.4 reveals a characteristic payoff pattern observed in the UG performed in this study. This figure plots the difference between human and virtual counterpart as a function of the total gain obtained by human participants. Then, a positive value in the ordinate means that the human player earned more money than the virtual counterplayer, whereas a negative value means the virtual player was winning more money than the human participant. It is interesting to notice that all participants except one (labelled ' $\mathrm{S} 1$ ' in Fig. 5.4) were earning less money than the virtual player when humans were playing the role of proposer. Conversely, human responders earned more money than virtual proposers.

Human responders accepted more often the offer than the virtual player did, such that this strategy of accepting more often led to overall higher gain. Even the participant labelled ' $\mathrm{S} 1$ ' earned more money as responder than proposer, even if he was the only one to always win over the virtual player. This result clearly showed that in our paradigm of the Ultimatum Game the responders tended always to earn more than the proposers, as shown by the red filled circles (human responders' total gain) on the right side and blue filled squares (human proposers' total gain) on the left side of the abscissa in Fig. 5.4. Another participant, labelled 'S2' in Fig. 5.4, behaved in a different way with respect to the other participants of the group. Participant 'S2' was indeed the only one to accept all kind of offers made by the proposer, thus behaving as a "rational" agent. Because of an equally distributed frequency of equanimous offered values (i.e. 5-5) and of winning and loosing offers the difference was zero between human participant and virtual player in the human responder condition.

\footnotetext{
${ }^{7}$ SPSS Inc., Chicago, Illinois.

${ }^{8}$ StataCorp LP, College Station, Texas.

${ }^{9}$ SD stands for standard deviation.

${ }^{10}$ In this case the $p$ value indicates the probability that the accepted offers from human and virtual responders are the same is 1 out of 1000 , and therefore is very low.
} 


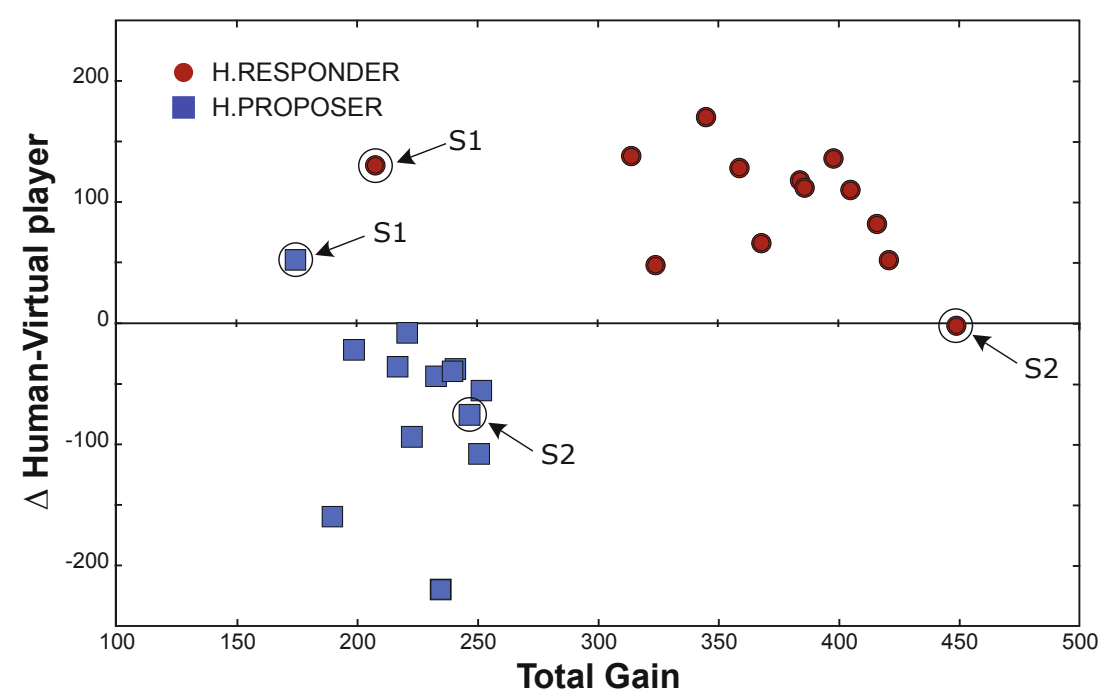

Fig. 5.4 Scatter plot of the total gain difference between Human and Virtual counterplayers. Human players acting as responders are indicated in red filled circles and human proposers in blue filled squares. The two subjects identified by the arrows showed the strategies discussed in the text.

To test whether gains differed for the virtual player and human subjects in the two experimental conditions (virtual proposer and human proposer) we conducted an Analysis of Variance (ANOVA) crossing virtual and human proposer with virtual and human responder on the total gain obtained in each experimental condition. Participants labelled 'S1' and 'S2' were excluded from this analysis because they expressed a kind of outlier behaviour with respect to the vast majority of the participants. Results (Figure 5.5, left side) showed that human responders gained more money when the virtual player made an offer and human participants were responders $(M=357.2, S D=73.1)$ rather than when human proposers made an offer $(M=275.2, S D=93.0), F(1,25)=17.79, p<0.001$. The same tendency occurred when the virtual player played the role of responder (Figure 5.5, right side) but the amount gained by the virtual player overall did not significantly differ according to the proposer. Thus, the average overall gain obtained by summing up the gains of both players was higher in the human responder condition $(M=632.5, S D=151.8)$ than in the human proposer condition $(M=519.2, S D=96.7), F(1,25)=5.14$, $p=0.05$.

\subsubsection{Effects of Emotional Priming}

We first analysed whether the average offer made by human proposers differed according to the emotional images in the background. A one-way ANOVA with type of image as the independent variable and amount of money offered as the 


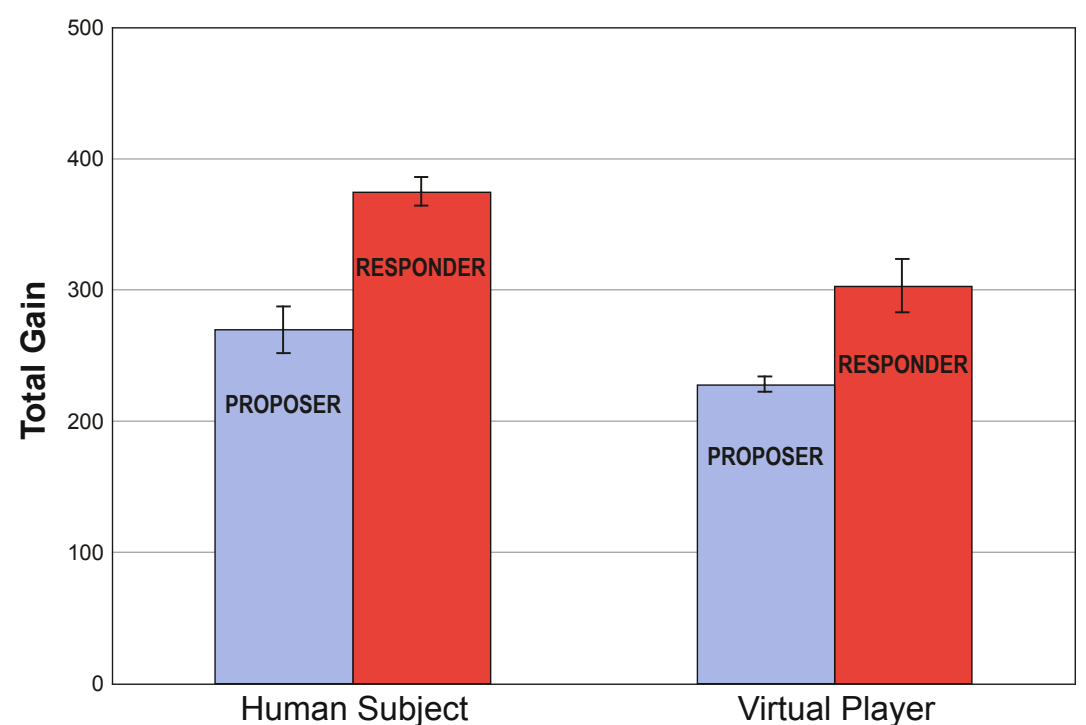

Fig. 5.5 Total gain as a function of the human subject (proposer vs. responder) and the virtual player (proposer vs. responder). Histograms show mean values and standard deviation computed over 11 participants.

dependent variable showed no significant effect. However, the investigation of differences in evaluating the emotional content of images showed that each participant rated the pictures in a very different manner. For example, one of the six images (number 1418) was perceived as inducing predominantly sadness and fear for participant 'S3', and predominantly joy and surprise for participant 'S13'. Thus, for each participant we employed an idiographic strategy and analysed results according to the emotions associated with each picture, rather than the picture itself. We also observed that one participant 'S5' provided the same exact emotional evaluation for each picture and we decided to exclude such subject from further analysis.

We conducted analyses across trials and we corrected for standard errors by clustering trials within each subject. This strategy allowed us to maintain an overall large number of trials (1080) while considering variability at the individual level (12 subjects). To investigate the effect of emotion on decision to accept or reject an offer, we conducted a logistic regression in which we regressed acceptance or rejection of the offer on the six basic emotions. The model was significant, as shown by the likelihood ratio chi-square test, which compares a model with the constant only to a model with our independent variables, in this case the six basic emotions: $\chi^{2}(5,12)=17.13, p<0.001$, with results showing that human proposers were more likely to offer a higher amount of money when making their offer in association with higher levels of joy, whose coefficient was marginally significant: $\beta(12)=$ $1.13, p=0.06$. These results suggest an association between valence of emotion, positive in this case, and economical decision. 
To further explore the influence of valence of emotion we analysed how ratings of the emotions associated with the pictures would aggregate in clusters of emotions and we found that indeed two clusters of emotions could be identified by aggregating positive emotions, in particular joy and surprise, and negative emotions, in particular disgust, fear, and sadness. Then we tested whether positive and negative emotions predicted the amount of money offered by human proposers. The model was significant, $F(1,12)=4.74, p=0.05$, with results showing that the cluster of negative emotions predicted the amount of money offered, $\beta(12)=0.50, p=0.05$.

\subsubsection{Effect of Personality on Economic Decision-Making}

In order to investigate the effect of personality traits on decision-making in the UG for each participant we aggregated the total gain earned by the participant and by the virtual player in each condition and the acceptance (i.e. the total number of offers accepted) by the responder counterpart. Then we calculated nonparametric correlations (we used the correlation coefficient Kendall's tau) with the personality traits. Personality traits were significantly correlated with economical decisionmaking only in the condition of human responder (Table 5.1] correlations above the diagonal), but not in the condition of human proposer (Table 5.1. correlations below the diagonal).

These results suggest that personality influenced participants' strategy as responders, but it did not affect their strategy as proposers. In this latter case it seems as if factors others than personality (for example emotion felt while making the decision) influenced participants' strategy. Regarding personality traits, more honest individuals gained more, less extraverted individuals accepted more often, and conscientiousness appeared the personality trait mostly related to the overall gain.

\subsubsection{Event-Related Potentials}

The analysis performed so far concerns only four subjects, for we will refrain from indicating statistical levels of significance. The analysis of the whole sample of subjects is under process and will be presented later as a separate paper. However, we present the most noticeable results that illustrate several data related with the taskrelated brain signals and brain circuits discussed in this study.

The visual inspection of ERPs revealed two distinct components at most electrode sites during both conditions of UG, proposer and responder. The first component is an early positive wave with a peak latency of about $200 \mathrm{~ms}$, identified as 'P200'. The second component is a negative wave peaking at about $350 \mathrm{~ms}$, identified as Feedback-Related Negativity, 'FRN'. Figures 5.6A and 5.6B show these waveforms in response to decision-making eliciting stimuli without [87, 113] and with emotional priming (studied here), respectively, along the midline at electrode positions $\mathrm{Fz}, \mathrm{FCz}, \mathrm{Cz}, \mathrm{CPz}$. The amplitude of both waves are larger towards the frontal areas. 


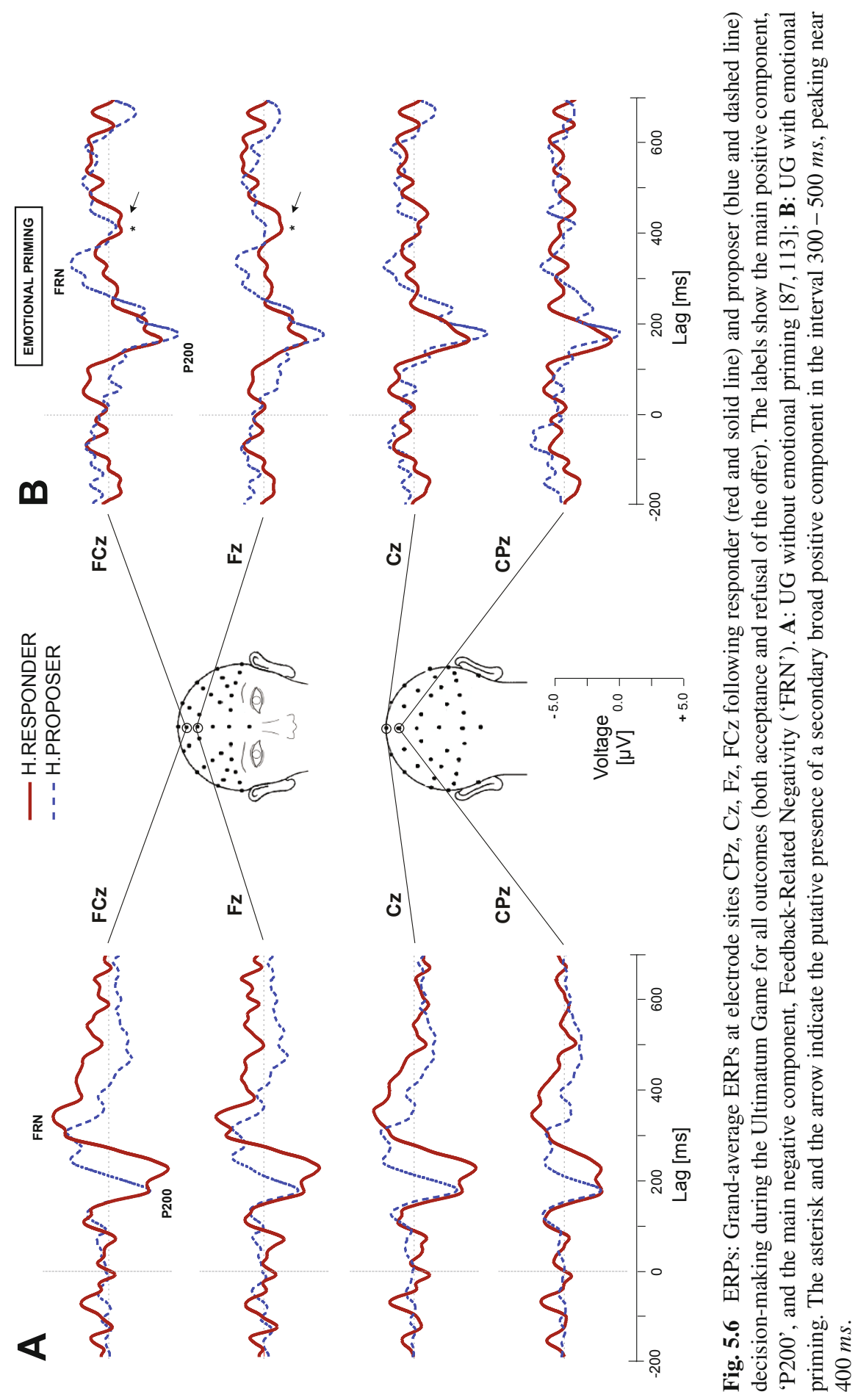


Table 5.1 This table shows correlations between participants' gain, computer's gain, acceptance rate, and personality traits $(N=12$ participants). Above the diagonal: results for virtual proposer/human responder. Below the diagonal: results for human proposer/virtual responder.

\begin{tabular}{|c|c|c|c|c|c|c|c|c|c|}
\hline & \multicolumn{9}{|c|}{ Human RESPONDER } \\
\hline & 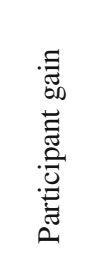 & 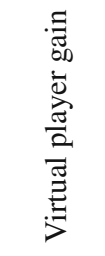 & 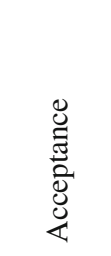 & 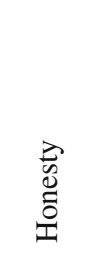 & 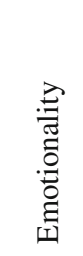 & 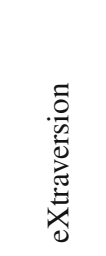 & 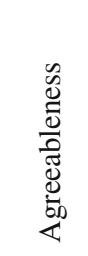 & 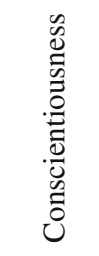 & 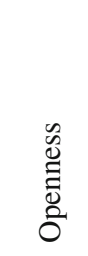 \\
\hline Participant gain & & .420 & $.809 *$ & $.515^{*}$ & .030 & -.430 & .230 & $.469 *$ & .198 \\
\hline Virtual player gain & .210 & . & $-.626 * *$ & .060 & -.150 & -.310 & -.050 & $.500 *$ & .076 \\
\hline Acceptance & $.504 *$ & $.718^{* *}$ & & .300 & -.120 & $-.421 *$ & .110 & $.464 *$ & .234 \\
\hline Honesty & .000 & .000 & -.110 & . & .050 & -.250 & .280 & .110 & .271 \\
\hline Emotionality & .250 & .060 & .050 & .190 & t & -.010 & .030 & -.150 & .013 \\
\hline eXtraversion & .000 & -.190 & -.020 & -.370 & .060 & . & -.130 & $-.470 *$ & .000 \\
\hline Agreeableness & .080 & -.140 & -.090 & .390 & -.300 & -.110 & . & .280 & $-.421 *$ \\
\hline Conscientiousness & .000 & .340 & .240 & .250 & -.300 & -.450 & .210 & . & -.040 \\
\hline Openness & -.110 & .200 & -.030 & .260 & .080 & -.050 & -.380 & .080 & . \\
\hline
\end{tabular}

The analysis of the latencies shows that without emotional priming (Fig. 5.6A) P200 was peaking with the same latency for proposer and responder decisionmaking. Moreover, in the responder condition without emotional priming an additional positive component, occurring after P200, was visible along all midline sites, but its amplitude was larger at frontal site (FCz). In Figure 5.6B the latency of P200 tended to be longer in the proposer condition, although the difference was not statistically significant. In the responder condition with emotional priming the second positive deflection (second small bump in the red curves at latencies near $240 \mathrm{~ms}$ was also increased towards the frontal areas ( $\mathrm{FCz}$ and $\mathrm{Fz}$ ). In addition, the second positive deflection was also observed in the proposer condition (blue dotted line). Notice that at electrode site Fz in Fig. 5.6B the superimposition of the FRN wave decreased the amplitude of the second positive component in the responder condition.

In the proposer condition FRN was larger at frontal sites irrespective of the emotional priming (blue dotted lines in Figures 5.6 A and 5.6 B). However, the emotional priming reduced the visibility of FRN component in the responder condition. This effect is likely to be due to the superimposition of a broad positive deflection peaking near $400 \mathrm{~ms}$, labelled with an asterisk and an arrow in Fig. 5.6B at electrode sites $\mathrm{FCz}$ and Fz.

Data from frontal electrode positions Fz, F1, F2, F3 and F4 displayed in Figure 5.7 emphasise the lateralization of FRN. The latency of FRN was bigger in 
proposer $v s$. responder condition at all sites, but in responder condition the amplitude of the wave was similar at all frontal sites. However, it is clearly visible that in the proposer condition at right frontal sites (F2 and F4) the amplitude of this wave was smaller than at left frontal sites (F1 and F3). In particular, the difference between the rightmost frontal site (F4) and the leftmost frontal site (F3) indicates that FRN appears to be associated to a lateralised cognitive process, as indicated by the left-sided arrows in Figre 5.7. In the responder condition P200 was larger at central site $\mathrm{Fz}$ than at lateral sites of either hemisphere. In the proposer condition the amplitude of P200 tended to be larger on the left hemisphere, somehow amplified by the occurrence of an early positive component (Fig. 5.7, the right-sided arrow at F3) peaking about $100 \mathrm{~ms}$ after the decision-making eliciting event.

Figure 5.8 shows five independent components (ICA-1 to ICA-5) accounting for most of ERP variance at location Fz between $200 \mathrm{~ms}$ and $350 \mathrm{~ms}$ without emotional priming [87]. For both experimental conditions, ICA-1 and ICA-5 fell into the same time-range as the corresponding P200 and FRN ERP components. The ICA-1 component accounted for $17 \%$ and $11 \%$ of variance in proposer and responder condition, respectively (Fig.5.8). The ICA-5 component, which explained 22\% of the variance for the proposer condition, and only $7 \%$ for the responder condition (Fig.5.8). Three ICA components (ICA-2 to ICA-4) were observed in proposer condition during the early part of FRN, whereas only two ICA components (ICA-3b and ICA-4b) were observed in the responder condition (Fig. 5.8). In the proposer condition, ICA-2, ICA-3 and ICA-4 explained 15\%, $17 \%$ and $34 \%$ of the variance, respectively. In the responder condition, ICA-3b and ICA-4b explained $9 \%$ and $18 \%$ of the variance, respectively. The topographic distributions of ICA components are presented on the right side of the corresponding ICA. Notice that ICA-5 is clearly lateralised during the proposer condition, thus confirming a different source during the responder condition, as shown previously at Figure 5.7 The complex distribution of the sources suggests the involvement of several brain circuits at different timing during the decision-making process.

\subsection{Discussion}

What role do affect and emotions play in economic decision-making and, more specifically, in willingness-to-share? Can we detect specific brain signals associated to these strategic choices? To this aim we decided to perform an iterative version of the Ultimatum Game, without a real payoff and with a human player facing a virtual counterplayer instructed to use a fair strategy that accept and propose also uneven shares. Most pictures used to induce emotional reactions are real-life figurative pictures, such as those of the Geneva Affective Picture Database (GAPED) [26] and those of the International Affective Picture System (IAPS) [11]. Such pictures have been shown to induce similar emotions in a large sample of people. However, figurative pictures necessarily evoke past experiences of the participant and are culturally related. We preferred to use non-figurative abstract pictures and to analyse emotions associated with pictures for each participant in an idiographic fashion. 


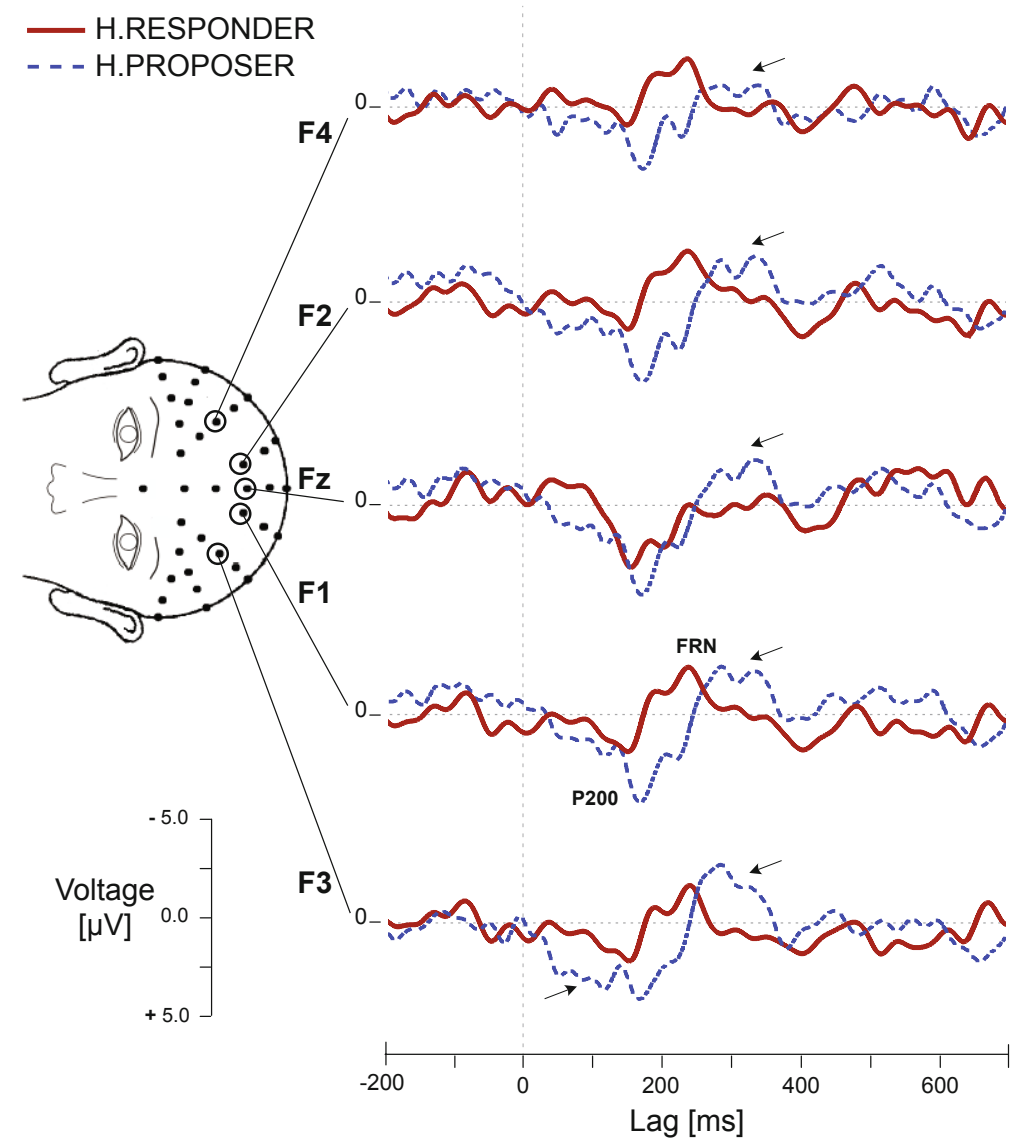

Fig. 5.7 ERPs: Grand-average ERPs at electrode sites F4, F2, Fz, F1, F3 following responder (red and solid line) and proposer (blue and dashed line) decision-making during the Ultimatum Game for all outcomes (both acceptance and refusal of the offer). The labels show the main positive component, 'P200', and the main negative component ('FRN'). The rightsided arrow indicates the presence of an early positive component at electrode site F3. The left-sided arrows indicate the FRN at all electrode sites in the proposer condition. Notice that the amplitude of FRN in the proposer condition is larger in the left hemisphere.

\subsubsection{The Strategy of Acceptance}

In the present sequential paradigm of the UG the proposer is constrained to guess the other party's response from the gains and losses experienced in the previous trials and tends to offer values more apart from the 5:5 share reported in a singleshot UG [93]. It is important to notice that participants played alternatively the role of proposer and responder, thus engaging them in a social scenario revealing their willingness-to-share. The proposer must constantly reevaluate the decision rule in order to optimise the next gain following an unpredictable outcome. This means that 

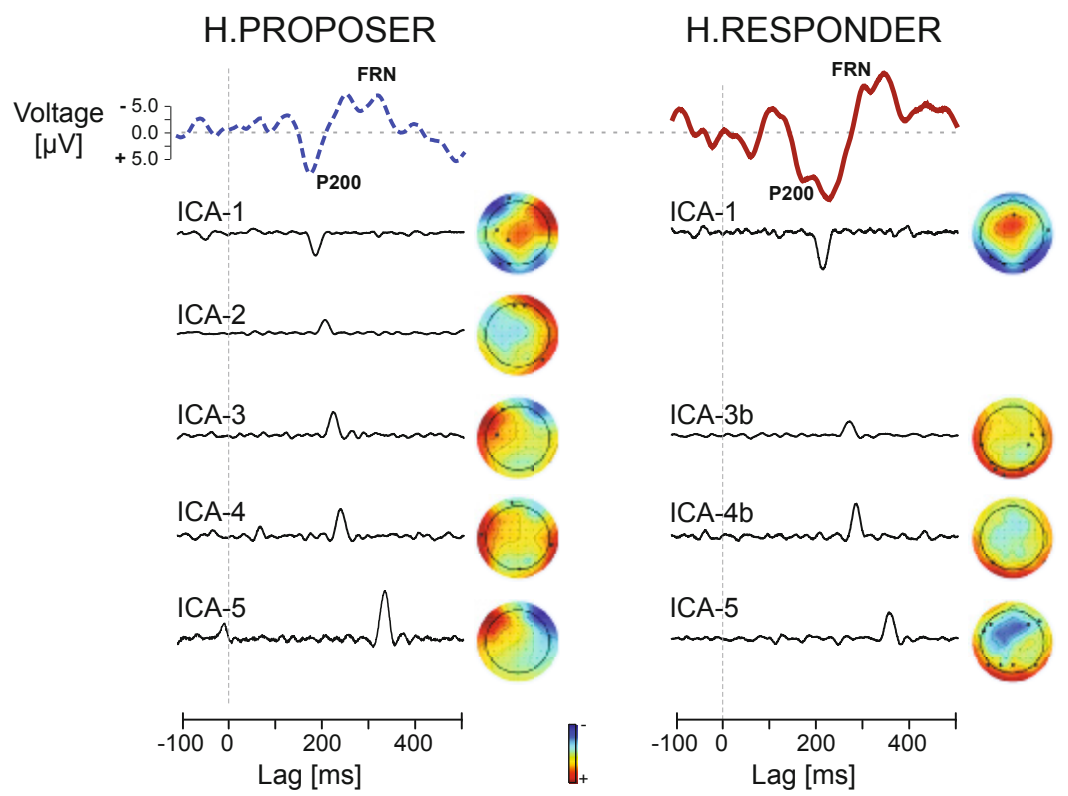

Fig. 5.8 Topographic distribution of independent component analysis of grand average ERPs at location Fz without emotional priming. Five components (ICA-1 to ICA-5) are predominantly activated for P200 and FRN. Time envelopes of ICA-components are time-locked with the ERP waveform for proposer and responder conditions. Notice the absence of ICA-2 in the responder condition. Adapted from [87].

when the proposer takes the initiative he takes more risks and our results show that, in this condition, the emotions significantly affect the choice made by the participant. At first glance this result may appear surprising because the other party is a virtual player, but the participants were not specifically informed of this fact. They were actually unaware of who is the counterplayer and at the end of the experimental session they usually reported to believe playing against another human player, the experimenter. This was demonstrated by the lack of main-effect significance in the factorial analysis of the total gains earned by human participants and by virtual players. When participants knew they were playing with a computer, the rejection rate was lower than when they explicitly knew they were playing with another person [106].

Unfair offers from friends are usually rated as being more unsatisfactory than those from strangers, whereas fair offers are rated as being equally satisfactory, then interaction with friends may involve increased fairness consideration in monetary distribution [120]. Results of the present study show that perceived emotions associated to the background pictures and individual differences influenced differently economical decision-making in the two experimental conditions. When individuals were playing the role of proposers, they tended to share a higher amount of money when their choice was made in association with negative emotions, in particular 
sadness and disgust. This result may be explained by the fact that participants tried to regulate a negative emotional state by being more altruistic [21]. Moreover, feeling negative emotions might have created a state of alert in participants, who responded by trying to create social bonds rather than by being competitive.

Unfair offers induce conflict in the responder between deliberative ("accept the offer") and affective ("reject the offer") motives [105]. However, any responder can unilaterally punish the unfair proposer with a rejection. Accepting or rejecting an offer is essential in social decision-making as these conditions enable the responder to contribute differentially to choices that are interpretable in terms of utility maximisation. This may explain why in our study we observed that responders tended to earn more money than proposers and why participants were less affected, if any, by emotional priming when they played the role of responder. When participants were playing the role of responders, they were more likely to accept an offer when their decision was made in association with positive emotions, such as joy and surprise. This result is aligned with studies demonstrating that a positive emotional state signals a benign situation and leads individuals to use simple heuristics and to not question too much the situation [107]. Offers in bargaining are likely to be guided by the emotions that proposers anticipate when contemplating their offers [89]. Positive offers may be driven by fear and guilt, where fear is more related to the perceived consequences of having one's offer rejected, and guilt is more related to concerns for the opponents' outcomes [89].

Accepting the offer posed surely less problems to the responder than rejecting it, in that rejection could have compromised the relationship with the other player, whereas acceptance conveyed willingness to maintain positive relationships even in the face of unfair offers. More conscientious individuals tended to accept more often, a result that is not particularly surprising given that this personality trait reflects tendency to accept rules rather than to question them. Interestingly, introverted individuals and more honest ones accepted more often, demonstrating compliance with the proposer's will. Indeed, more humble individuals tend to be more cooperative in the UG [54]. Beyond being more compliant, we also found that individuals accepting more often were those that made their decision in association with positive emotions. Higher rate of acceptance was associated with higher gain, thus the strategy of accepting more often paid off. Of note, our results suggest that the fact of accepting an offer was influenced by a person's disposition, rather than by the rational decision that any, even small, amount of money was better than nothing. Overall, it seems as if being in the 'happy-go-lucky' state of mind paid more than retaliating to an unfair offer with a rejection. It was reported that sadness was associated with higher rejection rate in the UG [50] and our results further support the idea that emotions play a fundamental role in decision-making. More conscientious individuals tended to accept more often, a result that is not particularly surprising given that this personality trait reflects tendency to accept rules and the status quo rather than to question them. 


\subsubsection{Event-Related Potentials}

A series of cognitive processes is involved when we go out for shopping and we face the dilemma of our willingness-to-pay with the willingness-to-sell of the other party. Whenever we extend this real-life situation to an iterative sequence of transactions aimed at maximising our willingness-to-share we always have to go through the perception of the stimuli (here visual), decision-making, response selection and response execution processes. In the present study, participants played alternatively the role of proposer and responder in block series of the Ultimatum Game, while we recorded their electroencephalogram (EEG) and analysed the ERPs triggered by the decision-making eliciting event. In this chapter we do not present data on ERPs related to the fairness of the share.

We observed several ERP components and the comparison between the two experimental conditions confirmed a positive-negative component waveform in the $150-400 \mathrm{~ms}$ time-range [113]. This waveform was more visible when participants made an offer (the proposer condition) and included a positive wave at a latency of about $200 \mathrm{~ms}$, 'P200', and a negative deflection, at about 250-300 $\mathrm{ms}$, the 'FRN'. Another positive deflection, likely to be associated with greater attentional and working memory resources activation, was sometimes following immediately the parieto-frontal P200. Overall, our results support the hypothesis that several distinct neural processes contribute to decision-making [8].

P200 is generated by the ventro-medial prefrontal cortex [68]. However, a shorter shift in the latency of a positive-negative wave complex in the $150-250 \mathrm{~ms}$ time range was reported during specific working memory processes of a "n-back task" [67] that involved top-down attention control primarily located over parietal electrodes [86]. Another study described the emergence of a positive component in a player that has to infer the current status of the rule from a relatively longer sequence of outcomes [6]. This cognitive task requires the development of strategies that involve attention and preservation of task-relevant information in working memory. In UG the proposer has to store a specific value in the in short-term memory buffer and, then, engage retrieval processes about the previous profit and stimulus-response choices to enable his offer after the instruction. An offer in the UG constrains the responder to guess the proposer's underlying rules from previous experiments of gains and losses. It is known that the type of strategies to learn rules of classification, conjunctions, or information integration is sensitive to cognitive, attentional, and load constraints [116]. The time range of the positive-negative complex observed in the present study exceeded the retrieval processes engaged in working memory, thus suggesting additional processes are involved, especially during the proposer condition.

Decision making triggered ERPs, similar to choice-locked frontal negativity, characterised by scaling with the risk of the decision in the anterior cigulate cortex [64, 125]. We observed that FRN was clearly distinguished between proposer and responder's conditions. Feedback concerning monetary loss elicited a negative deflection at the frontocentral regions compared with feedback concerning monetary gain [40, 53, 57]. The FRN was particularly well observed at frontal electrode sites during the proposer condition. A negative deflection, referred to as $\mathrm{N} 2$, is 
sensitive to tasks involving high level of conflict between competing responses [82, 123]. A second negative wave of similar topography, referred to as N400, that follows the N2 component was reported in cognitive control tasks that required conflict resolution [75, 76]. In an attentional orienting paradigm aimed to investigate which mechanisms facilitate processing of attended stimuli both semantic and emotional cues modulated negative ERP components (N400) associated to FRN [65]. The increase of high feedback outcome volatility was associated with FRN (i.e. the frontal N2/N400 components) [6], thus supporting the hypothesis that the FRN complex might be associated with the resolution of a conflict between competing responses following a change in the outcome rule [5, 10, 62, 121]. Rule-based classification for decision-making includes hypothesis generation and testing and relies on language shared by proposer and responder conditions.

In our study the topographical mapping of ICA components revealed one component (ICA-5) of FRN in both proposer and responder conditions. Notice that the ICA-5 component explained $22 \%$ of the variance for the proposer condition, and only $7 \%$ for the responder condition. Moreover, in the proposer condition, ICA2, ICA-3 and ICA-4 explained 15\%, $17 \%$ and $34 \%$ of the variance, respectively, whereas ICA-3b and ICA-4b explained only $9 \%$ and $18 \%$ of the variance, respectively. According to the literature the N400 component is strongly modulated by stimuli that require recognition and semantic manipulation and it is related to integration/unification processes of executive control [72]. This interpretation suggests that the participant was engaged in higher conflict-related resolution processes while engaged in the proposer condition. This could also explain the larger latency of FRN in the proposer $v s$. responder condition. Functional neuroimaging of source reconstruction of $\mathrm{N} 2$ peak revealed specific frontal regions engaged in the proposer condition, in particular the anterior cingulate activation, ACC [10].

The FRN is thought to reflect the impact of the midbrain dopamine signals on the ACC [56, 90]. The phasic decrease in dopamine input, elicited by negative prediction errors, would give rise to an increased ACC activity, associated with larger FRN amplitude. On the opposite, the phasic increase in dopamine signals, elicited by positive prediction errors, would decrease ACC activity, thus showing a smaller FRN amplitude. In our study we have also observed a strong lateralization of the FRN towards the left frontal areas in the proposer condition. It is interesting to notice that a left anterior P200 effect was observed in attentional orienting to emotional stimuli [65]. Recent study show that unfair offers in UG were rejected more frequently, evoked more negative emotional ratings and elicited larger FRN than fair offers [52]. FRN amplitude is smaller when an outcome is better than expected and larger when the outcome is worse than expected [57]. We will report our ERPs results related to fairness in a further study that will include a larger sample of participants.

\subsubsection{Conclusions}

Classic game theory would have predicted that proposers in the UG would offer the lowest amount possible and that respondents would accept any amount offered, to 
gain at least some money. We found that proposers tended to offer fair split and very rarely highly unbalanced offers. Positive emotions predicted higher acceptance rate, and negative emotions higher amount of money offered. Furthermore, human responders were more likely to accept an unfair offer when they were introverted, conscientious, and honest. Although a higher rate of acceptance was associated with higher gain, as the Game Theory would predict, our results show that factors others than rational choice may affect economical decision-making. These results support the hypothesis that participants based decisions on their willingness to share rather than on rational strategies. Importantly, decisions made were influenced by experienced emotions and dispositional traits [92]. In fact, emotions and individual differences predicted whether participants would accept an offer and how much money the proposer offered. Our results are in agreement with data showing that affect may differentially predict decision-making in the UG when participants played both parties, as proposers and as responders [50, 119]. Furthermore, our study introduces the role of personality and individual differences as factors affecting economical decision-making. In summary, our data corroborate previous findings indicating the importance of emotional processing in decision-making. Although results should be replicated with a larger sample, they suggest that Game Theory may be complemented by keeping into consideration the role of individual differences and emotional states in economical decision-making.

Acknowledgements. The Authors acknowledge the support of the Swiss National Science Foundation grant CR13I1-138032. The authors thank Pascal Missonnier and Vladyslav Shaposhnyk for their suggestions and contributions to the UG study without emotional priming.

\section{References}

1. Arbib, M.: From Mirror Neurons to Complex Imitation in the Evolution of Language and Tool Use. Annual Review of Anthropology 40(1), 257-273 (2011), doi:10.1146/annurev-anthro-081309-145722

2. Ashton, M.C., Lee, K.: A short measure of the major dimension of personality. European Journal of Psychological Assessment 91(4), 340-345 (2009)

3. Bault, N., Joffily, M., Rustichini, A., Coricelli, G.: Medial prefrontal cortex and striatum mediate the influence of social comparison on the decision process. Proc. Natl. Acad. Sci. U. S. A. 108(38), 16,044-16,049 (2011)

4. Bechara, A., Damasio, H., Tranel, D., Damasio, A.R.: The Iowa Gambling Task and the somatic marker hypothesis: some questions and answers. Trends Cogn. Sci. 9(4), 159-162 (2005)

5. Bentin, S., McCarthy, G.: Event-related potentials, lexical decision and semantic priming. Electroencephalogr. Clin. Neurophysiol. 60(4), 343-355 (1985)

6. Bland, A.R., Schaefer, A.: Electrophysiological correlates of decision making under varying levels of uncertainty. Brain Res. 12(1417), 55-66 (2011)

7. Boksem, M.A.S., De Cremer, D.: Fairness concerns predict medial frontal negativity amplitude in ultimatum bargaining. Social Neuroscience 5(1), 118-125 (2010), doi:10.1080/17470910903202666 
8. Bossaerts, P.: What decision neuroscience teaches us about financial decision making. Annual Review of Financial Economics 1(1), 383-404 (2009)

9. Botvinick, M., Cohen, J.D., Carter, C.S.: Conflict monitoring and anterior cingulate cortex: An update. Trends in Cognitive Sciences 111, 395-429 (2004)

10. Botvinick, M.M., Braver, T.S., Barch, D.M., Carter, C.S., Cohen, J.D.: Conflict monitoring and cognitive control. Psychol. Rev. 108(3), 624-652 (2001)

11. Bradley, M.M., Lang, P.J.: The international affective picture system (iaps) in the study of emotion and attention. In: Coan, J.A., Allen, J.J.B. (eds.) Handbook of Emotion Elicitation and Assessment, USA, pp. 29-46. Cambridge University Press, New York (2007)

12. Bush, G., Luu, P., Posner, M.I.: Cognitive and emotional influences in anterior cingulate cortex. Trends Cogn. Sci. 4(6), 215-222 (2000)

13. Bush, G., Whalen, P.J., Rosen, B.R., Jenike, M.A., McInerney, S.C., Rauch, S.L.: The counting stroop: an interference task specialized for functional neuroimagingvalidation study with functional mri. Hum. Brain Mapp. 6(4), 270-282 (1998)

14. Cameron, L.A.: Raising the Stakes in the Ultimatum Game: Experimental Evidence From Indonesia. Econ. Inq. 37(1), 47-59 (1999)

15. Carlin, A., Zilberstein, S.: Bounded Rationality in Multiagent Systems Using Decentralized Metareasoning. In: Guy, T.V., Kárný, M., Wolpert, D.H. (eds.) Decision Making with Imperfect Decision Makers. ISRL, vol. 28, pp. 1-28. Springer, Heidelberg (2012)

16. Carretié, L., Martín-Loeches, M., Hinojosa, J., Mercado, F.: Emotion and attention interaction studied through event-related potentials. Journal of Cognitive Neuroscience 13(8), 1109-1128 (2001)

17. Carretié, L., Mercado, F., Tapia, M., Hinojosa, J.A.: Emotion, attention, and the 'negativity bias', studied through event-related potentials. Int. J. Psychophysiol. 41(1), 75-85 (2001)

18. Carter, C.S., Braver, T.S., Barch, D.M., Botvinick, M.M., Noll, D., Cohen, J.D.: Anterior cingulate cortex, error detection, and the online monitoring of performance. Science 280(5364), 747-749 (1998)

19. Chang, Y.-H., Levinboim, T., Maheswaran, R.: The Social Ultimatum Game. In: Guy, T.V., Kárný, M., Wolpert, D.H. (eds.) Decision Making with Imperfect Decision Makers. ISRL, vol. 28, pp. 135-158. Springer, Heidelberg (2012)

20. Chase, H.W., Swainson, R., Durham, L., Benham, L., Cools, R.: Feedback-related negativity codes prediction error but not behavioral adjustment during probabilistic reversal learning. J Cogn Neurosci 23(4), 936-946 (2011), doi:10.1162/jocn.2010.21456

21. Cialdini, R.B., Kenrick, D.T.: Altruism as hedonism: A social development perspective on the relationship of negative mood state and helping. Journal of Personality and Social Psychology 34(5), 907-914 (1976)

22. Cohen, M.X., Elger, C.E., Ranganath, C.: Reward expectation modulates feedback-related negativity and EEG spectra. Neuroimage 35(2), 968-978 (2007), doi:10.1016/j.neuroimage.2006.11.056

23. Cowan, N.: Evolving conceptions of memory storage, selective attention, and their mutual constraints within the human information-processing system. Psychol. Bull. 104(2), 163-191 (1988)

24. Crino, P., Morrison, J., Hof, P.: Monoaminergic innervation of cingulate cortex. In: Neurobiology of Cingulate Cortex and Limbic Thalamus: a Comprehensive Handbook, vol. 285-310. Birkhauser, Boston (1993) 
25. Damasio, A.R., Tranel, D., Damasio, H.: Somatic markers and the guidance of behaviour: theory and preliminary testing. In: Levin, H.S., Eisenberg, H.M., Benton, A.L. (eds.) Frontal Lobe Function and Dysfunction, pp. 217-229. Oxford University Press, New York (1991)

26. Dan-Glauser, E.S., Scherer, K.R.: The Geneva affective picture database (GAPED): a new 730-picture database focusing on valence and normative significance. Behav. Res. Methods 43(2), 468-477 (2011)

27. Delorme, A., Makeig, S.: EEGLAB: an open source toolbox for analysis of singletrial EEG dynamics including independent component analysis. J. Neurosci. Methods 134(1), 9-21 (2004)

28. Devinsky, O., Morrell, M., Vogt, B.: Contributions of anterior cingulate cortex to behaviour. Brain 118, 279-306 (1995)

29. Eder, A.B., Hommel, B., De Houwer, J.: How distinctive is affective processing? on the implications of using cognitive paradigms to study affect and emotion. Cognition and Emotion 21(6), 1137-1154 (2007)

30. Ekman, P., Friesen, W.V., Ellsworth, P.: Emotion in the human face: guidelines for research and an integration of findings. Pergamon Press (1972)

31. Eriksson, J.L., Villa, A.E.P.: Event-related potentials in an auditory oddball situation in the rat. Biosystems 79(1-3), 207-212 (2005), doi:10.1016/j.biosystems.2004.09.017

32. Evans, K.M., Federmeier, K.D.: The memory that's right and the memory that's left: event-related potentials reveal hemispheric asymmetries in the encoding and retention of verbal information. Neuropsychologia 45(8), 1777-1790 (2007), doi:10.1016/j.neuropsychologia.2006.12.014

33. Falkenstein, M., Hohnsbein, J., Hoormann, J., Blanke, L.: Effects of crossmodal divided attention on late ERP components. ii. Error processing in choice reaction tasks. Electroencephalogr. Clin. Neurophysiol. 78(6), 447-455 (1991)

34. Fehr, E., Schmidt, K.: A Theory Of Fairness, Competition, and Cooperation. Quarterly Journal of Economics 114(3), 817-868 (1999)

35. Fellner, G., Güth, W.: What limits escalation?-Varying threat power in an ultimatum experiment. Economics Letters 80(1), 53-60 (2003)

36. Forgas, J.P., George, J.M.: Affective influences on judgments and behavior in organizations: An information processing perspective. Organizational Behavior and Human Decision Processes 86(1), 3-34 (2001)

37. Friedman, R., Anderson, C., Brett, J., Olekalns, M., Goates, N., Lisco, C.C.: The positive and negative effects of anger on dispute resolution: evidence from electronically mediated disputes. J. Appl. Psychol. 89(2), 369-376 (2004), doi:10.1037/00219010.89.2.369

38. Fuster, J.M.: The prefrontal cortex-an update: time is of the essence. Neuron 30(2), 319-333 (2001)

39. Gehring, W., Goss, B., Coles, M., Meyer, D., Donchin, E.: A neural system for error detection and compensation. Psychological Science 4(6), 385-390 (1993), doi:10.1111/j.1467-9280.1993.tb00586.x

40. Gehring, W.J., Willoughby, A.R.: The medial frontal cortex and the rapid processing of monetary gains and losses. Science 295(5563), 2279-2282 (2002)

41. de Gelder, B.: Towards the neurobiology of emotional body language. Nature Reviews Neuroscience 7(3), 242-249 (2006), doi:10.1038/nrn1872

42. Giard, M.H., Fort, A., Mouchetant-Rostaing, Y., Pernier, J.: Neurophysiological mechanisms of auditory selective attention in humans. Front Biosci. 5, 84-94 (2000)

43. Gneezy, U., Rustichini, A.: Pay enough or don't pay at all. The Quarterly Journal of Economics 115(3), 791-810 (2000) 
44. González-Roldan, A.M., Martínez-Jauand, M., Muñoz García, M.A., Sitges, C., Cifre, I., Montoya, P.: Temporal dissociation in the brain processing of pain and anger faces with different intensities of emotional expression. Pain 152(4), 853-859 (2011), doi:10.1016/j.pain.2010.12.037

45. Güth, W.: The Generosity Game and Calibration of Inequity Aversion. Journal of SocioEconomics 39, 155-157 (2010)

46. Güth, W., Schmittberger, R., Schwarze, B.: An experimental analysis of ultimatum bargaining. J. Econ. Behav. Organ. 3(4), 367-388 (1982)

47. Hajcak, G., Holroyd, C.B., Moser, J.S., Simons, R.F.: Brain potentials associated with expected and unexpected good and bad outcomes. Psychophysiology 42(2), 161-170 (2005), doi:10.1111/j.1469-8986.2005.00278.x

48. Hajcak, G., Moser, J.S., Holroyd, C.B., Simons, R.F.: The feedback-related negativity reflects the binary evaluation of good versus bad outcomes. Biol. Psychol. 71(2), 148154 (2006), doi:10.1016/j.biopsycho.2005.04.001

49. Härdle, W., Hildenbrand, W., Jerison, M.: Empirical Evidence on the Law of Demand. Econometrica 59, 1525-1549 (1991)

50. Harlé, K.M., Sanfey, A.G.: Incidental sadness biases social economic decisions in the ultimatum game. Emotion 7(4), 876-881 (2007), doi:10.1037/1528-3542.7.4.876

51. Henrich, J., Boyd, R., Bowles, S., Camerer, C., Fehr, E., Gintis, H., McElreath, R.: In search of Homo Economicus: Behavioral experiments in 15 small-scale societies. Am. Econ. Rev. 91(2), 73-78 (2001)

52. Hewig, J., Kretschmer, N., Trippe, R.H., Hecht, H., Coles, M.G., Holroyd, C.B., Miltner, W.H.: Why humans deviate from rational choice. Psychophysiology 48(4), 507514 (2011), doi:10.1111/j.1469-8986.2010.01081.x

53. Hewig, J., Trippe, R., Hecht, H., Coles, M.G.H., Holroyd, C.B., Miltner, W.H.R.: Decision-Making in Blackjack: An Electrophysiological Analysis. Cereb. Cortex 17, 865-877 (2007)

54. Hilbig, B.E., Zettler, I.: Pillars of cooperation: Honesty-humility, social value orientations, and economic behavior. Journal of Research in Personality 43(3), 516-519 (2009)

55. van Hoesen, G., Morecraft, R., Vogt, B.: Connections of the monkey cingulate cortex. In: Neurobiology of Cingulate Cortex and Limbic Thalamus: a Comprehensive Handbook. Birkhauser, Boston (1993)

56. Holroyd, C.B., Coles, M.G.: The neural basis of human error processing: reinforcement learning, dopamine, and the error-related negativity. Psychol. Rev. 109(4), 679-709 (2002)

57. Holroyd, C.B., Larsen, J.T., Cohen, J.D.: Context dependence of the event-related brain potential associated with reward and punishment. Psychophysiology 41(2), 245-253 (2004), doi:10.1111/j.1469-8986.2004.00152.x

58. Holroyd, C.B., Nieuwenhuis, S., Yeung, N., Cohen, J.D.: Errors in reward prediction are reflected in the event-related brain potential. Neuroreport 14(18), 2481-2484 (2003), doi:10.1097/01.wnr.0000099601.41403.a5

59. Houthakker, H.S.: Revealed Preference and the Utility Function. Economica 174, 159 174 (1950)

60. Hsee, C.K., Rottenstreich, Y.: Music, pandas, and muggers: on the affective psychology of value. J. Exp. Psychol. Gen. 133(1), 23-30 (2004)

61. Iacoboni, M.: Imitation, empathy, and mirror neurons. Annual Review of Psychology 60(1), 653-670 (2009), doi:10.1146/annurev.psych.60.110707.163604

62. Jia, S., Li, H., Luo, Y., Chen, A., Wang, B., Zhou, X.: Detecting perceptual conflict by the feedback-related negativity in brain potentials. Neuroreport 18(13), 1385-1388 (2007) 
63. Kahneman, D., Tversky, A.: Prospect Theory: An Analysis of Decision under Risk. Econometrica 47(2) (1979)

64. Kamarajan, C., Porjesz, B., Rangaswamy, M., Tang, Y., Chorlian, D.B., Padmanabhapillai, A., Saunders, R., Pandey, A.K., Roopesh, B.N., Manz, N., Stimus, A.T., Begleiter, H.: Brain signatures of monetary loss and gain: outcome-related potentials in a single outcome gambling task. Behav. Brain Res. 197(1), 62-76 (2009)

65. Kanske, P., Plitschka, J., Kotz, S.A.: Attentional orienting towards emotion: P2 and N400 ERP effects. Neuropsychologia 49(11), 3121-3129 (2011)

66. Keltner, D., Haidt, J.: Social functions of emotions at four levels of analysis. Cognition \& Emotion 13(505-521) (1999)

67. Kirchner, W.K.: Age differences in short-term retention of rapidly changing information. J. Exp. Psychol. 55(4), 352-358 (1958)

68. Knutson, B., Taylor, J., Kaufman, M., Peterson, R., Glover, G.: Distributed neural representation of expected value. J. Neurosci. 25(19), 4806-4812 (2005), doi:10.1523/JNEUROSCI.0642-05.2005

69. Kobza, S., Thoma, P., Daum, I., Bellebaum, C.: The feedback-related negativity is modulated by feedback probability in observational learning. Behav. Brain Res. 225(2), 396-404 (2011), doi:10.1016/j.bbr.2011.07.059

70. Kopelman, S., Rosette, A.S., Thompson, L.: The three faces of eve: strategic displays of positive, negative, and neutral emotions in negotiations. Organizational Behavior and Human Decision Processes 99, 81-101 (2006)

71. Krueger, F., Moll, J., Zahn, R., Heinecke, A., Grafman, J.: Event frequency modulates the processing of daily life activities in human medial prefrontal cortex. Cereb Cortex 17(10), 2346-2353 (2007)

72. Kutas, M., Federmeier, K.D.: Thirty years and counting: finding meaning in the N400 component of the event-related brain potential (ERP). Annu. Rev. Psychol. 62, 621-647 (2011)

73. Kutas, M., Hillyard, S.A.: Brain potentials during reading reflect word expectancy and semantic association. Nature 307(5947), 161-163 (1984)

74. Lane, A., Luminet, O., Rimé, B., Gross, J.J., de Timary, P., Mikolajczak, M.: Oxytocin increases the willingness to socially share one's emotions. International Journal of Psychology (2012)

75. Larson, M.J., Kaufman, D.A.S., Perlstein, W.M.: Neural time course of conflict adaptation effects on the stroop task. Neuropsychologia 47(3), 663-670 (2009)

76. Liotti, M., Woldorff, M.G., Perez, R., Mayberg, H.S.: An ERP study of the temporal course of the Stroop color-word interference effect. Neuropsychologia 38(5), 701-711 (2000)

77. Luce, M.F., Payne, J.W., Bettman, J.R.: Emotional Trade-Off Difficulty and Choice. Journal of Marketing Research 36, 143-159 (1999)

78. Luck, S.J., Hillyard, S.A.: Electrophysiological correlates of feature analysis during visual search. Psychophysiology 31(3), 291-308 (1994)

79. Makeig, S., Jung, T.P., Bell, A.J., Ghahremani, D., Sejnowski, T.J.: Blind separation of auditory event-related brain responses into independent components. Proc. Natl. Acad. Sci. U. S. A. 94(20), 10,979-10,984 (1997)

80. Makeig, S., Westerfield, M., Jung, T.P., Covington, J., Townsend, J., Sejnowski, T.J., Courchesne, E.: Functionally independent components of the late positive event-related potential during visual spatial attention. J. Neurosci. 19(7), 2665-2680 (1999)

81. Marshall, A.: Principles of Economics. An introductory Volume, 8th edn. Macmillan, London (1920) 
82. Mennes, M., Wouters, H., van den Bergh, B., Lagae, L., Stiers, P.: ERP correlates of complex human decision making in a gambling paradigm: detection and resolution of conflict. Psychophysiology 45(5), 714-720 (2008)

83. Miller, E.K., Cohen, J.D.: An integrative theory of prefrontal cortex function. Annu. Rev. Neurosci. 24, 167-202 (2001), doi:10.1146/annurev.neuro.24.1.167

84. Miltner, W.H., Braun, C.H., Coles, M.G.: Event-related brain potentials following incorrect feedback in a time-estimation task: Evidence for a "generic" neural system for error detection. J. Cognitive Neuroscience 9(6), 788-798 (1997), http://dx.doi.org/10.1162/jocn.1997.9.6.788

85. Miltner, W.H., Lemke, U., Weiss, T., Holroyd, C., Scheffers, M.K., Coles, M.G.: Implementation of error-processing in the human anterior cingulate cortex: a source analysis of the magnetic equivalent of the error-related negativity. Biol. Psychol. 64(1-2), 157166 (2003)

86. Missonnier, P., Leonards, U., Gold, G., Palix, J., Ibáñez, V., Giannakopoulos, P.: A new electrophysiological index for working memory load in humans. Neuroreport 14(11), 1451-1455 (2003)

87. Missonnier, P., Shaposhnyk, V., Lintas, A., Villa, A.E.P.: Responder's specific ERP cognitive component in the ultimatum game. In: Frontiers in Human Neuroscience Conference Abstract: XI International Conference on Cognitive Neuroscience (ICON XI), vol. 383 (2011), doi:10.3389/conf.fnhum.2011.207.00,383

88. Näätänen, R., Gaillard, A.W., Mäntysalo, S.: Early selective-attention effect on evoked potential reinterpreted. Acta. Psychol (Amst) 42(4), 313-329 (1978)

89. Nelissen, R.M.A., Leliveld, M.C., van Dijk, E., Zeelenberg, M.: Fear and guilt in proposers: Using emotions to explain offers in ultimatum bargaining. Eur. J. Soc. Psychol. 41(78-85) (2011)

90. Nieuwenhuis, S., Holroyd, C.B., Mol, N., Coles, M.G.: Reinforcement-related brain potentials from medial frontal cortex: origins and functional significance. Neurosci. Biobehav. Rev. 28(4), 441-448 (2004)

91. Nieuwenhuis, S., Slagter, H.A., von Geusau, N.J., Heslenfeld, D.J., Holroyd, C.B.: Knowing good from bad: differential activation of human cortical areas by positive and negative outcomes. Eur. J. Neurosci. 21(11), 3161-3168 (2005), doi:10.1111/j.1460-9568.2005.04152.x

92. Nowak, M.A., Page, K.M., Sigmund, K.: Fairness Versus Reason in the Ultimatum Game. Science 289(5425), 1773-1775 (2000)

93. Oosterbeek, H., Sloof, R., de Kuilen, G.V.: Cultural Differences in Ultimatum Game Experiments: Evidence from a Meta-Analysis. Experimental Economics 7(2), 171-188 (2004)

94. Picton, T.W., Bentin, S., Berg, P., Donchin, E., Hillyard, S.A., Johnson, R., Miller, G.A., Ritter, W., Ruchkin, D.S., Rugg, M.D., Taylor, M.J.: Guidelines for using human eventrelated potentials to study cognition: recording standards and publication criteria. Psychophysiology 37(2), 127-152 (2000)

95. Pillutla, M., Murnighan, J.: Unfairness, anger, and spite: Emotional rejections of ultimatum offers. Organizational Behavior and Human Decision Processes 68(3), 208-224 (1996)

96. Polezzi, D., Daum, I., Rubaltelli, E., Lotto, L., Civai, C., Sartori, G., Rumiati, R.: Mentalizing in economic decision-making. Behav. Brain. Res. 190(2), 218-223 (2008), doi:10.1016/j.bbr.2008.03.003

97. Pulskamp, R.J.: Correspondence of Nicolas Bernoulli concerning the St. Petersburg game (1713-1732). english translation. Tech. rep., Department of Mathematics \& Computer Science, Xavier University, Cincinnati, OH, USA (1999) 
98. Ritov, I.: Probability of regret: Anticipation of uncertainty resolution in choice. Organizational Behavior and Human Decision Processes 66(2), 228-236 (1996)

99. Rizzolatti, G., Craighero, L.: The Mirror-Neuron System. Annual Review of Neuroscience 27, 169-192 (2004), doi:10.1146/annurev.neuro.27.070203.144230

100. Roth, A., Prasnikar, V., Okuno-Fujiwara, M., Zamir, S.: Bargaining and market behavior in Jerusalem, Ljubljana, Pittsburgh, and Tokyo: An experimental study. Am. Econ. Rev. 81(5), 1068-1095 (1991)

101. Rotteveel, M., Phaf, H.: Mere exposure in reverse: Mood and motion modulate memory bias. Cognition \& Emotion 21(6), 1323-1346 (2007)

102. Rubinstein, A.: Perfect equilibrium in a bargaining model. Econometrica 50(1), 97-109 (1982)

103. Samuelson, P.A.: A Note on the Pure Theory of Consumer's Behaviour. Economica 5, 61-71 (1938)

104. Samuelson, P.A.: Consumption Theory in Terms of Revealed Preference. Economica 15, 243-253 (1948)

105. Sanfey, A.G., Chang, L.J.: Multiple Systems in Decision Making. Annals of the New York Academy of Sciences 1128(1), 53-62 (2008)

106. Sanfey, A.G., Rilling, J.K., Aronson, J.A., Nystrom, L.E., Cohen, J.D.: The neural basis of economic decision-making in the Ultimatum Game. Science 300(5626), 1755-1758 (2003)

107. Schwarz, N.: Emotion, congnition, and decision making. Cognition and Emotion 14(4), 433-440 (2000)

108. Simpson, J.R., Drevets, W.C., Snyder, A.Z., Gusnard, D.A., Raichle, M.E.: Emotioninduced changes in human medial prefrontal cortex: Ii. during anticipatory anxiety. Proc. Natl. Acad. Sci. U. S. A. 98(2), 688-693 (2001), doi:10.1073/pnas.98.2.688

109. Slonim, R., Roth, A.E.: Learning in High Stakes Ultimatum Games: An Experiment in the Slovak Republic. Econometrica 66(3), 569-596 (1998)

110. Slovic, P., Finucane, M.L., Peters, E., MacGregor, D.G.: The affect heuristic. In: Gilovich, D.K.T., Griffin, D. (eds.) Heuristics and Biases: The Psychology of Intuitive Judgment. Cambridge University Press, New York (2002)

111. Storbeck, J., Clore, G.L.: On the interdependence of cognition and emotion. Cogn. Emot. 21(6), 1212-1237 (2007)

112. Thaler, R.H.: From Homo economicus to Homo sapiens. Journal of Economic Perspectives 14, 133-141 (2000)

113. Villa, A.E.P., Missonnier, P., Lintas, A.: Neuroheuristics of Decision Making: From Neuronal Activity to EEG. In: Guy, T.V., Kárný, M., Wolpert, D.H. (eds.) Decision Making with Imperfect Decision Makers. ISRL, vol. 28, pp. 159-194. Springer, Heidelberg (2012)

114. Vogt, B.A., Finch, D.M., Olson, C.R.: Functional heterogeneity in cingulate cortex: the anterior executive and posterior evaluative regions. Cereb Cortex 2(6), 435-443 (1992)

115. Von Neumann, J., Morgenstern, O.: Theory of Games and Economic Behavior. Princeton University Press (1944)

116. Waldron, E.M., Ashby, F.: The effects of concurrent task interference on category learning: evidence for multiple category learning systems. Psychon. Bull. Rev. 8(1), 168-176 (2001)

117. World Medical Association.: World Medical Association Declaration of Helsinki: Ethical principles for medical research involving human subjects. JAMA 284(23), 30433045 (2000)

118. van't Wout, M., Chang, L.J., Sanfey, A.G.: The influence of emotion regulation on social interactive decision-making. Emotion 10(6), 815-821 (2010),

doi: $10.1037 / \mathrm{a} 0020069$ 
119. van't Wout, M., Kahn, R.S., Sanfey, A.G., Aleman, A.: Affective state and decisionmaking in the ultimatum game. Exp. Brain Res. 169(4), 564-568 (2006), doi:10.1007/s00221-006-0346-5

120. Wu, Y., Leliveld, M.C., Zhou, X.: Social distance modulates recipient's fairness consideration in the dictator game: an erp study. Biol. Psychol. 88(2-3), 253-262 (2011), doi:10.1016/j.biopsycho.2011.08.009

121. Yang, J., Zhang, Q.: Electrophysiological correlates of decision-making in high-risk versus low-risk conditions of a gambling game. Psychophysiology 48(10), 1456-1461 (2011), doi:10.1111/j.1469-8986.2011.1202.x

122. Yasuda, A., Sato, A., Miyawaki, K., Kumano, H., Kuboki, T.: Error-related negativity reflects detection of negative reward prediction error. Neuroreport 15(16), 2561-2565 (2004)

123. Yeung, N., Nieuwenhuis, S.: Dissociating response conflict and error likelihood in anterior cingulate cortex. J. Neurosci. 29(46), 14,506-14,510 (2009)

124. Yeung, N., Sanfey, A.G.: Independent coding of reward magnitude and valence in the human brain. J. Neurosci. 24(28), 6258-6264 (2004), doi:10.1523/JNEUROSCI.453703.2004

125. Yu, R., Zhou, X.: To bet or not to bet? The error negativity or error-related negativity associated with risk-taking choices. J. Cogn. Neurosci. 21(4), 684-696 (2009)

126. Zeelenberg, M., Beattie, J., van der Pligt, J., de Vries, N.K.: Consequences of regret aversion: Effects of expected feedback on risky decision making. Organizational Behavior and Human Decision Processes 65(2), 148-158 (1996) 